\title{
The Optimal Level and Impact of Internal Factors on Growth
}

\author{
Kui-Wai Li \\ Department of Economics and Finance, and APEC Study Center, College of Business, City University of Hong Kong, \\ Hong Kong, China \\ E-mail:efkwli@cityu.edu.hk
}

Received May 5, 2011; revised June 15, 2011; accepted June 25, 2011

\begin{abstract}
This paper empirically uses data from the world economy to show that performance of domestic factors are equally important to external factors when comes to growth. Various external and domestic factors are used to construct two separate indices and the principal component method is applied in the analysis. The empirical results show that given a different level of performance in the economy's external factors, a higher performance in the internal factors will produce a higher growth rate. When the performance of an economy's internal factors is extremely low, it would be appropriate for that economy first to improve its internal factors.
\end{abstract}

\section{Keywords: Economic Openness, Domestic Factors, Globalization Index, Principle Component Analysis, World} Growth

\section{Introduction}

In the debate on economic growth, the neo-classical school argues that capital and labor are exogenous factors in production, while technological advancement embraces a number of non-measurable factors. In contrast, the "new growth theory" advocates the importance of endogenous factors that incorporates human capital and a number of institutional and domestic factors, such as the level of corruption and protection of property rights.[1-3] Exogenous factors are quantifiable and are derived from outside the economic system, and examples include such external factors as export, foreign direct investment, tourism and international transfers. Endogenous factors are unquantifiable and are derived from within the economic system; examples include such internal factors as education spending, political stability, rule of law and other institutional factors.

Empirical growth studies have produced a mixed result in the impact of different factors on growth and globalization. While external factors are considered crucial gains in the gains process of globalization, critics have considered the costs of globalization in terms of domestic factors. [4-14] Similarly, the construction of globalization indices have popularly been based on a mixture of external and domestic factors. [15-18] Other cross-country empirical studies have identified a great number of domestic and geographical factors that have various degrees of impact on growth.[19-26]

Although the performance of the external factors contribute to economic growth, the link between the external factors and an economy's growth performance in the global community depend to a considerable extent on how well internal factors have performed.[27] A more matured capital market, for example, will facilitate a greater capital flow, while a more transparent, corruption-free investment environment could attract more foreign direct investment. Successful performance of internal factors can complement the performance of external factors in the growth and globalization process.

The performance of both external factors and internal factors can impact on growth directly, but there is also an indirect link between internal factors and growth. The good performance in internal factors can exercise an additional and positive influence on the performance of external factors, which in turn can have a greater impact on growth. It is probable that internal factors can influence economic growth directly, and can indirectly impact on growth through a better performance in external factors. As such, the internal factors can be the more fundamental factors to growth than external factors.[25-26]

This paper empirically investigates the hypothesis that internal factors are the more fundamental factors to growth than external factors. Two separate indices for 
external factors and internal factors will first be constructed. Instead of examining the impact of a single factor each of the two indices is constructed from a total of 17 factors.[22,24,28] Regression analysis shows how the two groups of factors can independently impact on growth. To show how the internal factors can exert independent influence on growth, a simulation analysis is used to find the optimal level of performance in each economy's internal factors. Lastly, the sample world economies are mapped according to their performance in the external factors and internal factors. The empirical result shows that economies will have to achieve a certain level in the performance of the internal factors before they can take advantage of the performance in external factors. The data sources of the 34 factors for the 62 world economies for the period 1998-2002 are given in the Appendix.

Section II uses the principal component analysis method to work out the two indices for the external factors and internal factors. Section III gives the regression estimates, while section IV compiles an optimal level of performance in each economy's internal factors and a simulation study is conducted to show how the 62 world economies performed in the two types of factors. Section $\mathrm{V}$ concludes the paper.

\section{The Two Indices}

Instead of pulling different factors into a single globalization index, this section constructs two separate indices on the external factor and internal factors. Kearney [15] grouped the external factors into the four categories of economic integration, technological connectivity, personal contacts and international engagement. Kearney's selection of external factors and categories can be improved by incorporating the inter-industry trade and intra-industry trade indicators. In theory, trade statistics are post-trade data that reflect the outcome of trade policies and show the actual quantity of export and import. An economy's inter-industry trade is traditionally based on comparative advantage. In intra-industry trade, eco- nomies export and import the same good or service in a given period. Thus, intra-industry trade reflects more on the varieties of goods the economy enjoys due to industrial diversity and technological advancement than simply trade flows based on comparative advantages. The calculation of the inter-industry and intra-industry trade indicators is shown in the Appendix. The External Factors Index $(E F I)$ is constructed from a total of 17 external economic openness factors grouped under six categories.

The choice of internal factors used to construct the Internal Factors Index (IFI) is chosen from the list in Dur- lauf. [19] The 17 internal factors are classified into three broad categories. While the first category of institutional establishment is considered as proxy measures for civility, security and protection of individuals, the other two categories provide indicators on the quality of life. Appendix Table 1 summarizes the categories of external factors and internal factors. Both the external and internal factors are normalized on a yearly basis before they are used to construct the two indices. ${ }^{1}$ [29]

The principal component analysis (PCA) is used to construct the two indices. There are several advantages in using the PCA method. First, the PCA is meant to give weightings that maximize the variance of the indices. Since the factors are likely to be correlated, the PCA reduces the number of factors to capture the maximum variation. Secondly, the PCA method can commensurate on the different measurement units of these factors. Most importantly, the PCA method selects the weights by the data itself. [30] The principal components are extracted from the correlation matrix of the variables, in a way that they accounted for the highest percentage of variation. The PCA is applied to each individual year instead of applying one PCA to the whole sample period. This has the advantage of incorporating various changes in the sample period, and can eliminate the impact of a sudden change in any particular year that could affect other sample years. $^{2}$

We adopt a latent variable model and postulate that the index is linearly dependent on a set of observable factors $(V)$ and an error term. The principal components (PCs) are computed from the following procedure:

$$
\left\{\begin{array}{c}
P C_{1}=\alpha_{11} V_{1}+, \cdots,+\alpha_{1 \Psi} V_{\Psi} \\
P C_{2}=\alpha_{21} V_{1}+, \cdots,+\alpha_{2 \Psi} V_{\Psi} \\
\vdots \\
P C_{L}=\alpha_{L 1} V_{1}+, \cdots,+\alpha_{L \Psi} V_{\Psi}
\end{array}\right.
$$

where $\alpha_{11}, \alpha_{12}, \cdots, \alpha_{1 \Psi}$ are elements of eigenvector $\alpha_{1}=\left\{\alpha_{11}, \cdots, \alpha_{1 \Psi}\right\}$, and there are a total of $\mathrm{L}$ eigenvectors, which are determined by the data. A total of $L$ principal components are computed using successive eigenvectors elements, $\alpha_{1}, \alpha_{2}, \cdots, \alpha_{L}$, corresponding to the largest $L$ eigenvalues, $\lambda_{1}>\lambda_{2}>\cdots>\lambda_{L}$, of the factor correlation matrix. The first principal component, $P C_{1}$, of the linear combination with maximal variance becomes our EFI,

\footnotetext{
${ }^{1}$ The normalization formulas for the high and low value variables are: $V_{i t}=\left(v_{i}-\min \left\{v_{1}, \cdots, v_{N}\right\} /\left\{\max \left(v_{1}, \cdots, v_{N}\right)-\min \left(v_{1}, \cdots, v_{N}\right)\right\}\right)$, and$$
\left.V_{i t}=\left(\max \left\{v_{1}, \cdots, v_{N}\right\}-v_{i} /\left\{\max \left(v_{1}, \cdots, v_{N}\right)-\min \left(v_{1}, \cdots, v_{N}\right)\right\}\right)\right)_{t} \cdot V_{i t} \text { is }
$$

variable $V$ of economy $i$ at time $t$.

${ }^{2}$ This is seen as an improvement to Andersen and Herbertsson ${ }^{[16]}$ whom use a single principle component for all years, and to Dreher ${ }^{[18]}$ whom uses weightings of year 2000 for the calculation of indices for all years from 1970 to 2000 .
} 
Table 1. Pooled-GLS Estimates of 62 World Economies, 1998-2002.

\begin{tabular}{|c|c|c|c|c|}
\hline Coefficients & $k=3$ & $k=4$ & $k=8$ & $k=10$ \\
\hline$\alpha$ & $\begin{array}{c}7.5159 \\
(0.0722)^{*}\end{array}$ & $\begin{array}{c}7.3161 \\
(0.0861)^{*}\end{array}$ & $\begin{array}{c}7.5144 \\
(0.0967)^{*}\end{array}$ & $\begin{array}{c}7.5269 \\
(0.0956)^{*}\end{array}$ \\
\hline$\beta_{1}$ & $\begin{array}{c}0.2904 \\
(0.0270)^{*}\end{array}$ & $\begin{array}{c}0.3591 \\
(0.0360)^{*}\end{array}$ & $\begin{array}{l}-0.0324 \\
(0.0911)\end{array}$ & $\begin{array}{c}-0.0868 \\
(0.0920)\end{array}$ \\
\hline$\beta_{2}$ & $\begin{array}{c}0.3036 \\
(0.0073)^{*}\end{array}$ & $\begin{array}{c}0.2260 \\
(0.0163)^{*}\end{array}$ & $\begin{array}{c}0.3593 \\
(0.0729)^{*}\end{array}$ & $\begin{array}{c}0.3916 \\
(0.0739)^{*}\end{array}$ \\
\hline$\beta_{3}$ & $\begin{array}{c}0.3690 \\
(0.0097)^{*}\end{array}$ & $\begin{array}{c}0.3472 \\
(0.0174)^{*}\end{array}$ & $\begin{array}{c}0.4956 \\
(0.0730)^{*}\end{array}$ & $\begin{array}{c}0.5224 \\
(0.0731)^{*}\end{array}$ \\
\hline$\beta_{4}$ & & $\begin{array}{c}0.3421 \\
(0.0188)^{*}\end{array}$ & $\begin{array}{c}0.5961 \\
(0.0750)^{*}\end{array}$ & $\begin{array}{c}0.5561 \\
(0.0749)^{*}\end{array}$ \\
\hline$\beta_{5}$ & & & $\begin{array}{c}0.6334 \\
(0.0762)^{*}\end{array}$ & $\begin{array}{c}0.6447 \\
(0.0759)^{*}\end{array}$ \\
\hline$\beta_{6}$ & & & $\begin{array}{c}0.7027 \\
(0.0766)^{*}\end{array}$ & $\begin{array}{c}0.6757 \\
(0.0770)^{*}\end{array}$ \\
\hline$\beta_{7}$ & & & $\begin{array}{c}0.6847 \\
(0.0777)^{*}\end{array}$ & $\begin{array}{c}0.7346 \\
(0.0771)^{*}\end{array}$ \\
\hline$\beta_{8}$ & & & $\begin{array}{c}0.6894 \\
(0.0779)^{*}\end{array}$ & $\begin{array}{c}0.7523 \\
(0.0782)^{*}\end{array}$ \\
\hline$\beta_{9}$ & & & & $\begin{array}{c}0.7342 \\
(0.0787)^{*}\end{array}$ \\
\hline$\beta_{10}$ & & & & $\begin{array}{c}0.7427 \\
(0.0788)^{*}\end{array}$ \\
\hline F-test ${ }^{\dagger}$ & 0.0000 & 0.0000 & 0.0000 & 0.0000 \\
\hline Adj. $R^{2}$ & 0.999704 & 0.999624 & 0.999670 & 0.999745 \\
\hline Wald Test ${ }^{\dagger}$ & 0.0000 & 0.0000 & 0.0000 & 0.0000 \\
\hline
\end{tabular}

Notes: Figures in parentheses are standard errors. $*$ and $\dagger=$ significance at $1 \%$ and $5 \%$ levels, respectively.

which is then normalized or scaled. ${ }^{3}$ The scaled EFI will take a value of unity when an economy has the best performance in its external environment. The same procedures are applied to the construction of the Internal Factors Index (IFI).

Appendix Table 2 gives the five-year (1998-2002) average of the EFI and IFI. The ranking based on the five-year average shows that the top 10 economies in the two indices are mainly advanced economies in North America and Western Europe. Most of the remaining European Union economies are included when the scores are extended to the top 20. Singapore and Hong Kong are the only two Asian economies in the top 20 of both indicators. We observe that an economy can vary between the two indices. For example, Japan ranked $18^{\text {th }}$ in the
$I F I$, but ranked $26^{\text {th }}$ in the $E F I$, while Indonesia ranked $44^{\text {th }}$ and $55^{\text {th }}$ in EFI and IFI, respectively. Economically weaker economies tend to rank lower in the two indicators. Effectively, economies that ranked below $30^{\text {th }}$ are all developing economies.

\section{Regression Estimates}

The hypothesis that economies with strong performance in internal factors enjoy a higher rate of per capita GDP growth at different level of performance in the external factors is examined. The IFI is divided into $k$ portions using percentiles, shown in Equation (2), with $N$ being the number of economies.

For example, the IFI of year $t$ is divided into three portions, so $k=3$, with 33.33 percent of the economies in each portion. The first portion is made up of the minimum IFI in year $t$ to the 33rd IFI in year $t$. A dummy variable, $D_{\kappa}$, where $\kappa=1, \cdots, k$, is assigned to each of the last $(k-1)$ portions of IFI, namely $D_{2}, \cdots D_{k}$. The $D_{k}$ dummy takes a value of unity if $I F I_{\text {it }}$ falls into the $\kappa^{\text {th }}$ portion, otherwise it takes a value of zero. An economy with $D_{\kappa}=1$ has a better internal environment than an economy with $D_{\kappa-1}=1$.

The following model is used to examine how internal factors can affect the outcome of external factors:

$$
\begin{aligned}
\ln y_{i t}= & \alpha+\beta_{1} \ln E F I_{i t}+\beta_{2} \ln E F I_{i t} * D_{2, i t} \\
& +\cdots+\beta_{k} \ln E F I_{i t} * D_{k, i t}+\varepsilon_{i t},
\end{aligned}
$$

where $y_{i t}$ is the real GDP per capita deflated by the purchasing power parity of economy $i$ at time $t$. For economy $i$ who has the dummy $D_{\kappa}=1$, the regression equation become:

$$
\ln y_{i t}=\alpha+\left(\beta_{1}+\beta_{\kappa}\right) \ln E F I_{i t}+\varepsilon_{i t} .
$$

For another economy $j$ has the dummy $D_{\kappa-c}=1$, for any $c>0$. In other words, when economy $j$ 's internal environment is not as good as economy i's, the regression equation become:

$$
\ln y_{j t}=\alpha+\left(\beta_{1}+\beta_{\kappa-c}\right) \ln E F I_{j t}+\varepsilon_{j t} .
$$

If a higher performance in internal factors brings a

$$
\begin{gathered}
I F I_{t}=\left\{\min _{i}\{I F I\}, \cdots,\left(\frac{100}{k} \% * N\right)^{t h} I F I\right\},\left\{\left(\left(\frac{100}{k}+1\right) \% * N\right)^{t h} I F I, \cdots,\left(\left(2 \times \frac{100}{k}\right) \% * N\right)^{t h} I F I\right\}_{t}, \cdots, \\
\left\{\left(\left((k-1) \times \frac{100}{k}+1\right) \% * N\right)^{t h} I F I, \cdots,\left(\left(k \times \frac{100}{k}\right) \% * N\right)^{t h} I F I\right\}_{t} .
\end{gathered}
$$

${ }^{3}$ Scaled $E F I_{i t}=\left(E F I_{i}-\min _{i}\{E F I\} / \max _{i}\{E F I\}-\min _{i}\{E F I\}\right)_{t}$ 
Table 2. The EFI - IFI matrix of world economies, 1998-2002 average.

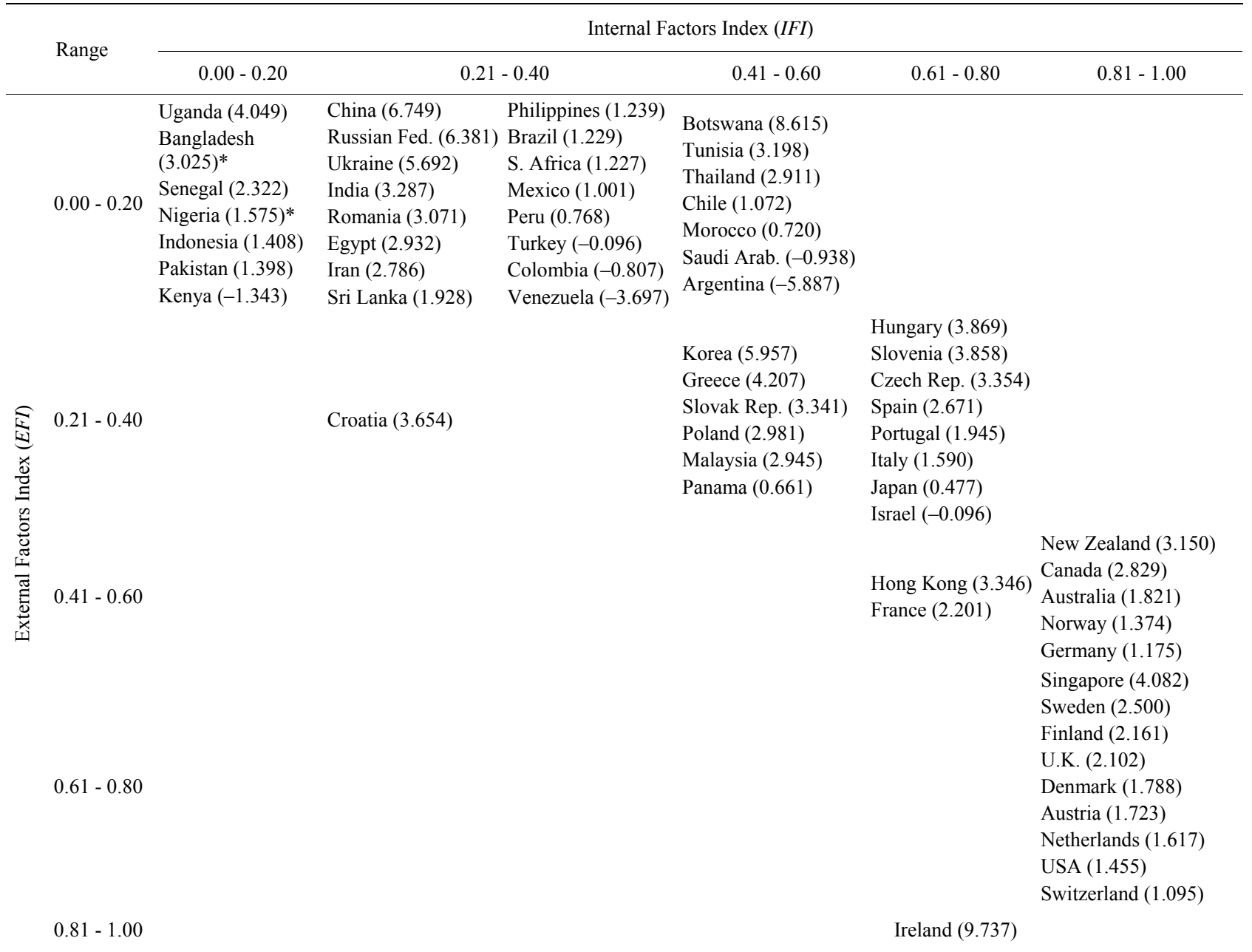

Note: Figures in parenthesis are the percentage growth rates of the average 1999-2002 GDP per capita (purchasing power parity in constant 2000 price). ${ }^{*}$ Countries with IFI $<0$.

higher marginal effect of external factors on economic growth, we expect to see $\beta_{1}+\beta_{\kappa-c}<\beta_{1}+\beta_{\kappa}$. Thus, generalizing all the $k$ dummy variables, and if a better internal environment has a positive impact of external factors on growth, we expect to see $\beta_{1}<\beta_{1}+\beta_{2}<$ $\beta_{1}+\beta_{3}<\cdots \beta_{1}+\beta_{k}$, suggesting that a strong performance in an economy's internal factors enables an economy to benefit more from performance in external factors.

Two Wald tests are conducted to show the significance of the coefficient estimates. The first Wald test is to see if a low performance in the internal factors will constrain economic growth. An alternative hypothesis with $\beta_{1}<0$ implies that if an economy has an extremely weak performance in its internal factors (reflected in the IFI value falling into the first partition of the index), external factors would bring negative effects on economic growth, namely:

$$
\begin{aligned}
& H o^{1}: \beta_{1}=0 \\
& H a^{1}: \beta_{1}<0 .
\end{aligned}
$$

The second Wald test shows that an economy's IFI can significantly affect the marginal effect of an economy's external factors on its real per capita GDP growth rate:

$$
\begin{aligned}
& H o^{2}: \beta_{1}+\beta_{\kappa}=0 \text { for } \kappa=2, \cdots, k . \\
& H a^{2}: \beta_{1}+\beta_{\kappa-1}<\beta_{1}+\beta_{\kappa} \text { for } \kappa=3, \cdots, k .
\end{aligned}
$$

The alternative hypothesis, $\mathrm{Ha}^{2}$, states that economies that have a better performance in their internal factors should benefit more from performance in external factors.

The pooled-GLS with White-Heteroskedasticity consistent standard error and covariance is applied to estimate Equation (3), which is estimated with $k=3,4,8$ and 10. Table 1 shows the empirical estimation of the 
pooled-GLS results for the 62 countries for the sample period of 1998-2002. All estimates with $k=3$ and $k=4$ in Table 1 are significant at 1 percent level. In these two cases, the estimate for $\beta_{1}$ is not negative, but is significantly different from zero, suggesting that a low performance in internal factors does not adversely affect the effect on economic growth, though this may be due to the small size of $k$. When the size of $k$ is small, the marginal effect of internal factors on economic growth may not be obvious. The F-tests reject the null hypothesis of Equation (3), suggesting that as economies improve their performance in internal factors, the marginal effect on growth increases.

For estimates with $k=8$ and $k=10$, and with the exception of the insignificant estimate for $\beta_{1}$, all the estimates are significance at 1 percent level. For these estimated values of $k$, the estimate of $\beta_{1}$ is negative, which means that a low performance in internal factors of an economy can adversely affect growth. Similarly, the F-tests also reject the null hypothesis as in the cases of $k$ $=3$ and $k=4$.

\section{Optimal Performance in Internal Factors}

This section uses a simulation method to work out the optimal performance in the internal factors in order to achieve a maximum gain in economic growth. From the estimation result of $k=4,8$ and 10 in Table 1, we first examine economies with top scores in IFI to see if there is diminishing returns in the external factors. Hypothetical economies are compared in order to see how their growth performs given a different level of performance in internal factors.

Two hypotheses are postulated. First, given two externally homogeneous economies (namely, economies with same performance in the EFI), heterogeneity in the performance of IFI will lead to differences in economic growth. Secondly, given homogeneity in the performance of IFI among different economies, those economies with a better performance in EFI will result in higher economic growth.

The empirical result with $k=10$ in Table $\mathbf{1}$ is used to simulate the growth of per capita GDP for a total of 100 hypothetical economies with an incremental change of 0.01 in the IFI that ranged from zero to one. The different values of the EFI are either below or above the median value. A simulated series of per capita GDP figures are generated from the empirical results with $k=10$ in Table 1. ${ }^{4}$ The simulated per capita GDP growth rates are

${ }^{4}$ For example, when $E F I=0.25$, and with $D_{3, i t}=1$ (namely, the range of IFI is between 0.2 and 0.3 , and other dummies take a zero value), the simulated GDP per capita growth is 8.92904 (i.e. $7.52687+$ $(-0.08675) * \ln (0.25 * 100)+(0.522359) * \ln (0.25 * 100) * 1)$. plotted against the IFI, and a step function is presented separately for the four values of EFI (at $0.25,0.45 .0 .75$ and 0.95) as shown in Figure 1.

The first observation in Figure $\mathbf{1}$ is that economies with a higher performance in external factors (with higher EFI) produce a higher level of per capita GDP growth at all level of IFI above 0.1. In economies with IFI below the median, a higher performance in EFI always produces a higher economic growth, except when IFI is below 0.1 . The second observation is that, when the IFI is above median, economic growth keeps rising regardless of the performance in the EFI until an economy's IFI reaches the range of 0.7 and 0.8 , beyond which the growth rate of per capita GDP declines. This suggests that the 0.7 to 0.8 range of the IFI is the optimal level, and economies will reach their highest possible growth rates given their EFI. When the value of EFI lies between 0 and 1 , the marginal contribution of IFI to the per capita GDP growth of an economy is positive if the value of IFI lies between 0 and the optimal level. When the value of IFI is above its optimal level, the marginal contribution of IFI to an economy's GDP per capita growth is negative. ${ }^{5}$

In short, if an economy has an IFI value below 0.1 , a lower value of EFI actually produces a higher per capital GDP growth. So long as the value of IFI lies above 0.1, the marginal contribution by the different level of EFI to per capita GDP growth is positive. On the contrary, when IFI lies between 0 and 0.1 , the marginal contribution of EFI to per capita GDP growth is negative. ${ }^{6}$

The marginal effect of both EFI and IFI can be examined from plotting the change in the per capita GDP growth rate against the IFI at different level of the EFI, Figure 2 shows that a higher EFI can lead to a larger change in the growth rate of per capita GDP at different level of IFI. ${ }^{7}$ However, as shown in Figure 3, the marginal effect of IFI on the change in growth rate of per capita GDP at different level of EFI is increasing at a decreasing rate. Furthermore, Figure 3 shows that when the EFI value is below the median, its marginal contribution to growth is larger than that when EFI is above the

$\overline{5}$ This can also be seen if Equation (3) is modeled as a continuous or differentiable function, where $0<i<1$, and $I F I^{*}$ represents the optimal value:

$$
\left.\frac{\partial \ln y}{\partial I F I}\right|_{0<I F I<\text { Median,EFI=EFI }}>0 ;\left.\frac{\partial \ln y}{\partial I F I}\right|_{I F I<I F I^{*} ; E F I=E F I_{i}}>0 ;\left.\frac{\partial \ln y}{\partial I F I}\right|_{I F I>I F I^{*} ; E F I=E F I_{i}}<0
$$

${ }^{6}$ When the function is a differentiable, the results can be summarized as follows: $\left.\frac{\partial \ln y}{\partial \ln E F I}\right|_{0.5<I F I<1}>0 ;\left.\frac{\partial \ln y}{\partial \ln E F I}\right|_{0.1<I F I<0.5}>0 ;\left.\quad \frac{\partial \ln y}{\partial \ln E F I}\right|_{0<I F I<0.1}<0$ ${ }^{7}$ The marginal effect can be summarized as follows when a differentiable equation is used:

$\left.\frac{\partial \ln y}{\partial I F I}\right|_{E F I=0.25}<\left.\frac{\partial \ln y}{\partial I F I}\right|_{E F I=0.45}<\left.\frac{\partial \ln y}{\partial I F I}\right|_{E F I=0.75}<\left.\frac{\partial \ln y}{\partial I F I}\right|_{E F I=0.95}$ 


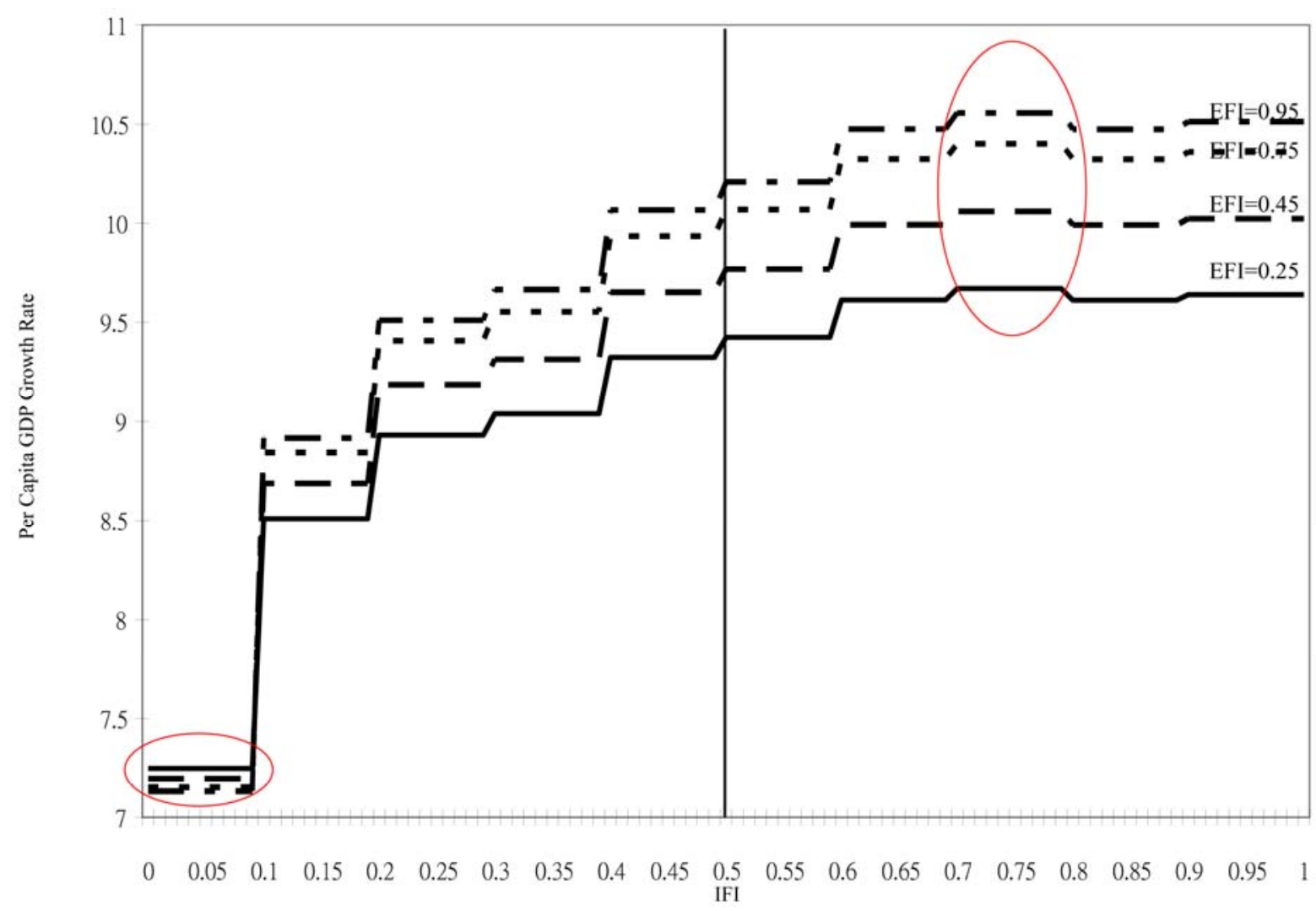

Figure 1. Effect of external factors on growth.

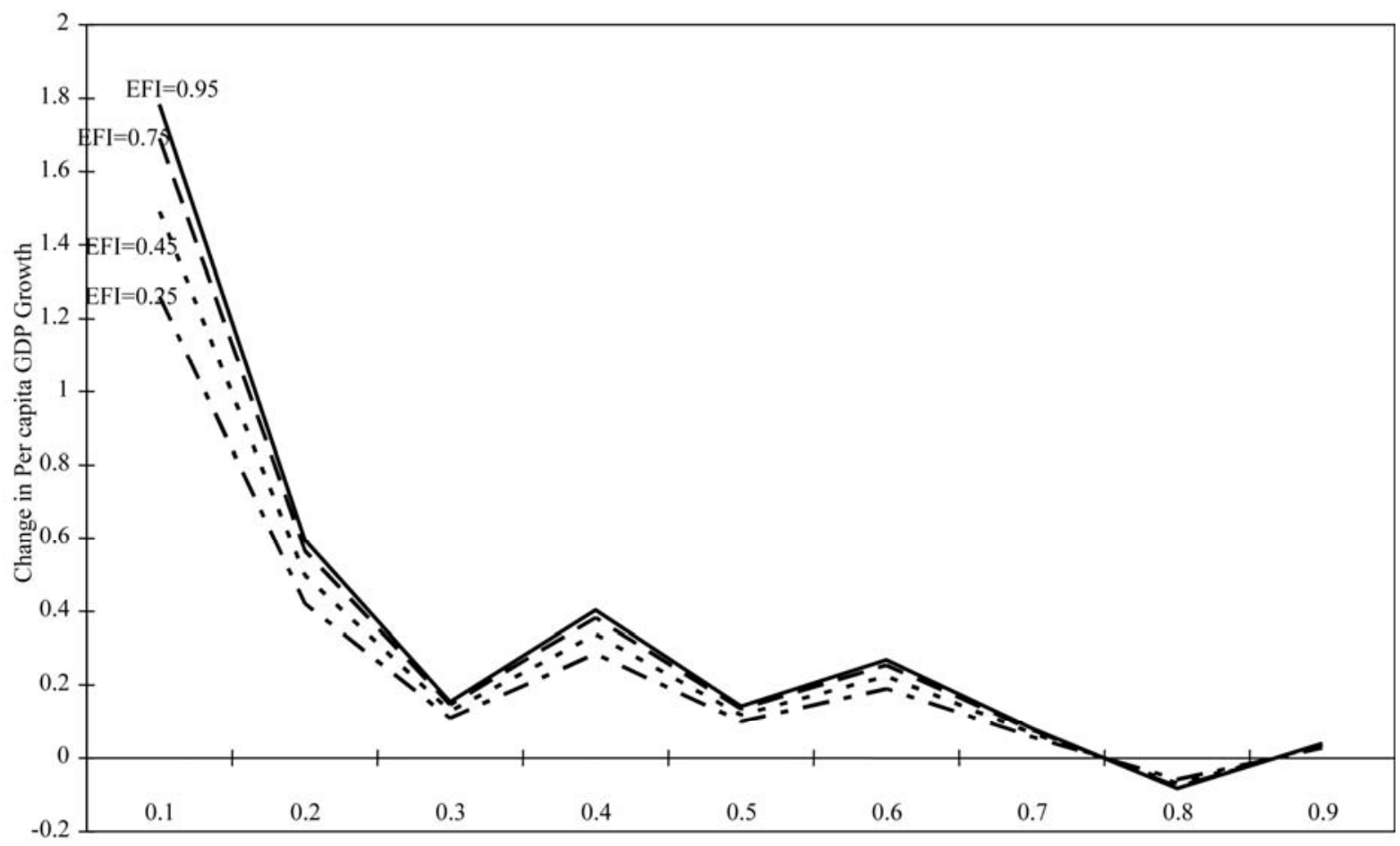

IFI

Figure 2. Marginal effect of EFI on growth. 
median. ${ }^{8}$

With the construction of the two indices that look separately at internal factors and external factors, the regression and simulation results can provide additional evidence to support other studies that internal factors can have independent influence on growth. [17] Various policy recommendations can be suggested from the empirical and simulation analysis. Firstly, a more global economy indicated by the higher performance in the external factors does not always lead to higher economic growth. Instead, those economies with $0<I F I<0.1$ should improve their IFI in order to reap additional gain from economic openness and globalization. Secondly, economies whose IFI is above 0.1 , but below the optimal range ( 0.7 to 0.8 ), should aim to improve the performance of the internal factors.

A summary pattern of relationship between economic growth and the performance in the external factors and internal factors seems to have emerged from the simulation analysis. Figure 4 shows that once the performance in the internal factors has reached a minimum level, improvement in internal factors will lead to a larger per capita GDP growth rate at every higher level of EFI. Thus, at a high level of external factors, $\mathrm{EFI}_{3}$ for example, a higher level of per capita GDP growth rate can be achieved.

To see how the 62 world economies perform in the 1998-2002 period, Table 2 maps out the sample period average in five different ranges of EFI and IFI. Individual economies can consider their own positions in the ranking of the two indices, and compare their performance with other economies, including the periodic average in the per capita GDP growth rates. There are seven mainly poor developing economies (Bangladesh, Indonesia, Kenya, Nigeria, Pakistan, Senegal and Uganda) that have the lowest rankings in both indices. On the contrary, those economies that performed strongly in both EFI and IFI are mainly developed economies (Austria, Denmark, Finland, Netherlands, Singapore, Sweden, Switzerland, United Kingdom and USA). Most developed economies have performed stronger in IFI than in $E F I$. Ireland is the only economy that has a stronger performance in EFI than in IFI in the sample period. ${ }^{9}$

One observation from Table 2 is that performance of internal factors is the relevant constraint in the growth of any economy. Most economies that are strong in the performance of IFI are also strong in the performance of $E F I$, but not the reverse. In other words, it would be ap-

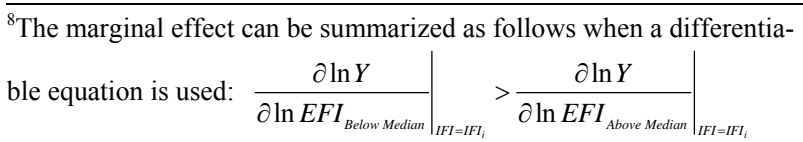

${ }^{9}$ Measured in purchasing power parity constant 2000 price, Ireland's GDP per capita is highest among the 62 world economies. propriate for economies to improve their internal conditions and environment before they can gain from openness and globalization. A good performance in internal factors is essential to growth and development. There are a number of economies (Argentina, Botswana and so on) that have achieved the median in IFI, but show low performance in EFI. The 0.61 to 0.80 range of the IFI seems to be the critical range, as virtually all industrialized advanced economies achieved an IFI score above 0.61 .

Table 2 shows that a number of economies in the second lowest $(0.21-0.40)$ range of IFI experience a relative high growth rate in the sample period. For example, China has a growth rate of 6.749 percent and the Russian Federation had 6.381 percent and so on. This suggests that these economies have to improve their IFI before further reaping the gain from economic openness and globalization. Among the developing economies, African economies (e.g. Uganda, Kenya and Senegal) are the weakest performers in both the EFI and IFI, while the middle-ranking economies are the few Asian (e.g. Thailand and Malaysia) and Latin American (e.g. Panama and Chile) economies. Other Asian economies (e.g. India, Indonesia, Philippines and Sri Lanka) have performed poorly in both EFI and IFI. The group of developing economies that have reached the range of 0.61 0.80 in the IFI are mostly Eastern European economies (e.g. Hungary, Slovenia and Czech Republic), which will probably be the next group of countries that would benefit from globalization. The lesson is that sound performance in the various internal factors will facilitate good performance of external factors. In short, advancement in the performance of internal factors will help promoting economic openness.

\section{Conclusions}

The empirical results in the paper clarify the importance of internal factors in growth and globalization. The reasonable large number of factors used in the construction of the two indices provides a comprehensive picture on the performance of different economies. The regression result that internal factors are important in promoting an economy's growth has led to further investigation and analysis in the relationship of the two types of factors. Given a different level of performance in the economy's external factors, a higher performance in the internal factors will produce a higher growth rate. When the performance of an economy's internal factors is extremely low, it would be appropriate for that economy first to improve its internal factors.

In short, performance in the internal factors is the more fundamental condition than performance in the external factors. Before the "optimal" level of internal 


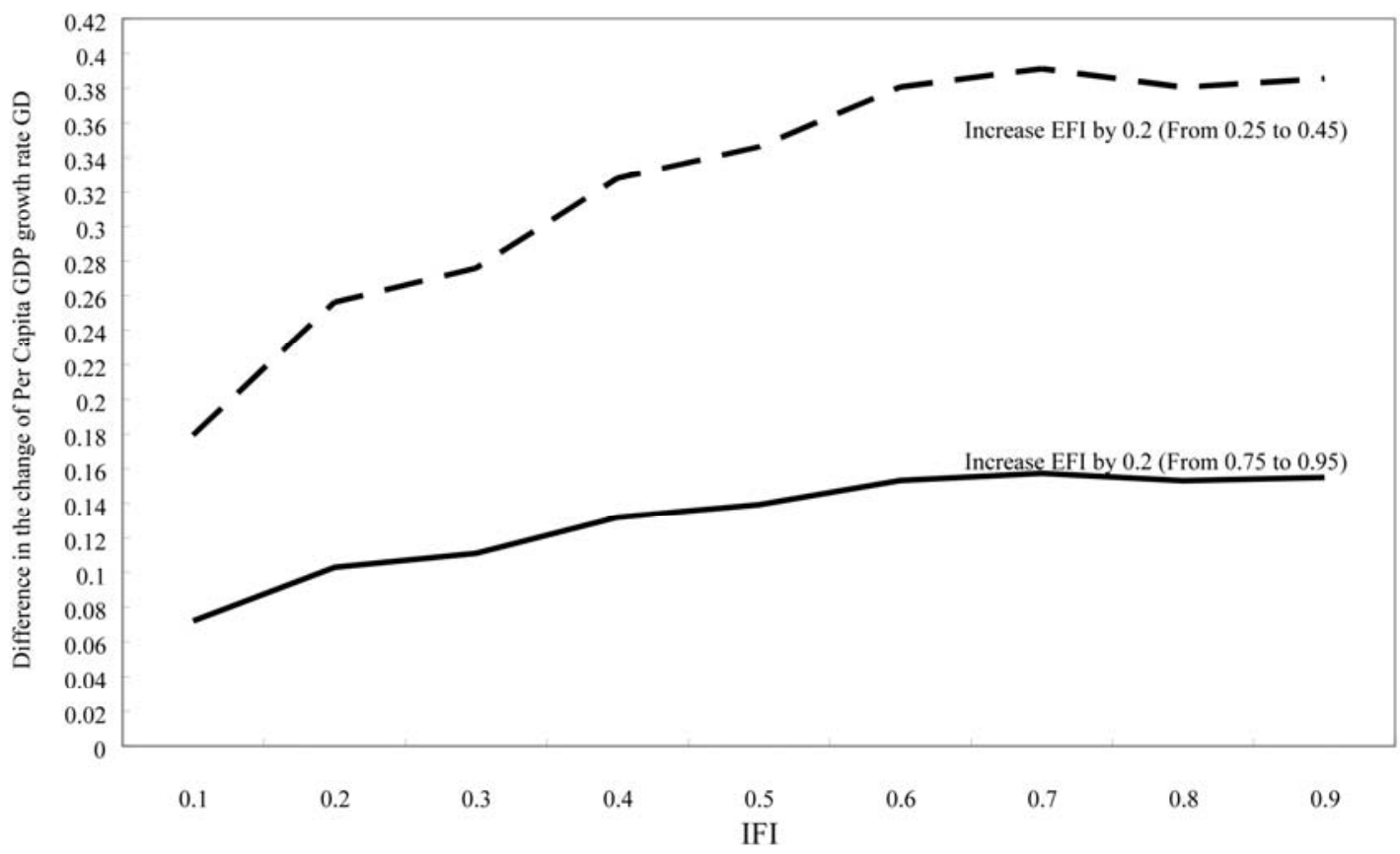

Figure 3. Effect of a change in EFI.

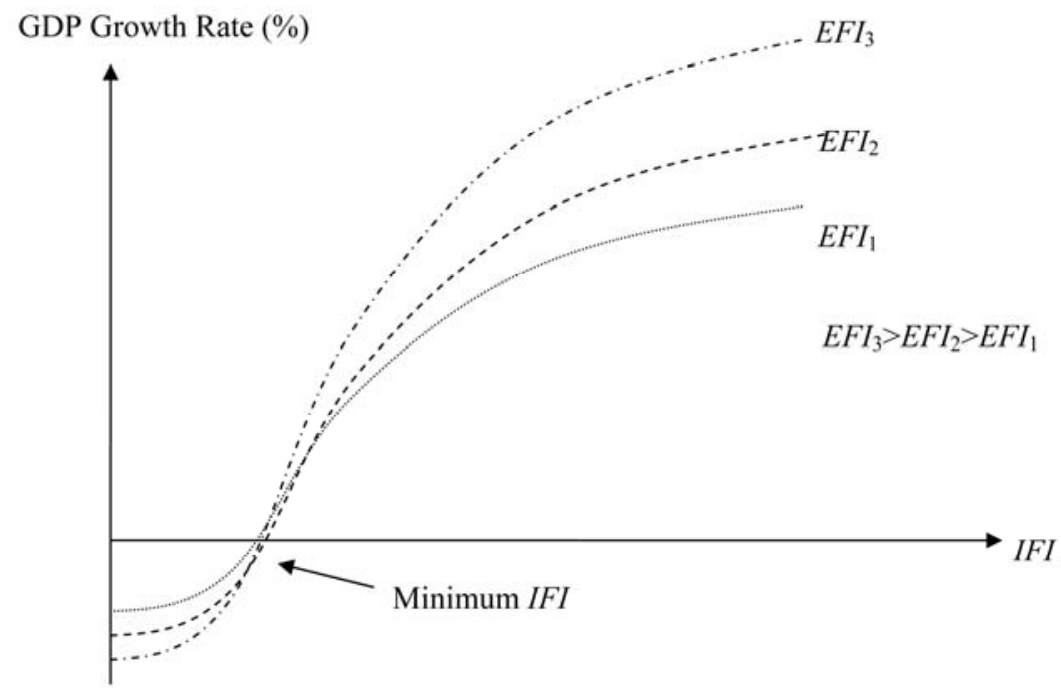

Figure 4. Relationships between growth, external and internal factors.

factors is reached, economies will experience a rise in their per capita GDP as their performance of internal factors improve. The empirical results in this paper lend further support on the importance of a sound performance in domestic factors.[31-32] Economies with strong performance in external factors and globalization have sound performance in their internal factors. For those world economies that are ranked low in the Internal Factor Index, appropriate economic policies should be conducted to improve the performance of internal factors. The conclusion that the internal or institutional factors are more fundamental to growth than external factors adds to the debate on the difference between the two types of factors, or the contribution of single factors.[24, 28]

Despite the useful empirical findings and the policy lessons economies can draw on, there can be a number of possible drawbacks in this paper. One is the selection of factors in the two categories. It is possible that different factors selection would produce different empirical results, and the use of 34 external and internal factors can provide sufficient representation. The problem of possi- 
ble overlap among factors can partly be alleviated by the advantages of the principal component analysis. [33-34]

\section{Acknowledgements}

The author is indebted to comments from Barbara Stallings, Neantro Saavedra-Rivano, Gianluca F. Grimalda, Peter J. Newell, Eden Yu, participants in the 2006 meeting of the APEC Study Center Consortium and colleagues in the brown-bag seminar of the Department of Economics and Finance, City University of Hong Kong. An earlier version of this paper has been published as a Working Paper in the Center for the Study of Globalisation and Regionalism, University of Warwick. The two research assistants, Iris Pang and Michael Ng, have provided excellent research support. The funding support from the City University of Hong Kong under the Strategic Research Grant (Number 7002433) is gratefully acknowledged. The author is solely responsible for the remaining errors.

\section{References}

[1] P. M. Romer, "Increasing Returns and Long Run Growth," Journal of Political Economy, Vol. 94, No. 5, 1986, pp. 1002-1037. doi:10.1086/261420

[2] P. M. Romer, "Endogenous Technological Change," Journal of Political Economy, Vol. 98, No. 5, 1990, pp. S71S102. doi: $10.1086 / 261725$

[3] R. E. Lucas Jr., "On the Mechanics of Economic Development," Journal of Monetary Economics, Vol. 22, No. 2, 1988, pp. 3-42. doi:10.1016/0304-3932(88)90168-7

[4] L. Winters, "Trade Policies for Poverty Alleviation," In: B. Hoekman, A. Mattoo and P. English, Eds., Development, Trade and the WTO: A Handbook, The World Bank, Washington D.C., 2002, pp. 28-38.

[5] A. Deardorff and R. Stern, "What You Should Know about Globalization and the World Trade Organization," Review of International Economics, Vol. 10, No. 3, 2002, pp. 404-423. doi:10.1111/1467-9396.00340

[6] J. Bhagwati, "In Defense of Globalization," Oxford University Press, New York, 2004.

[7] E. Aisbett, "Why are the Critics so Convinced that Globalization is Bad for the Poor?" Working Paper No. 11066, National Bureau of Economic Research, 2005.

[8] J. Frankel, "Globalization of the Economy," Working Paper 7858, National Bureau of Economic Research, 2000.

[9] R. Falvery and E. Kreickemeier, "Globalization and Factor Returns in Competitive Markets," Journal of International Economics, Vol. 66, No. 1, 2005, pp. 233-248. doi:10.1016/j.jinteco.2004.04.004

[10] E. Edmonds and N. Pavcnik, "Does Globalization Increase Child Labor? Evidence from Vietnam," Working Paper 8760, National Bureau of Economic Research,
2002.

[11] M. Feldstein, "Aspects of Global Economic Integration: Outlook for the Future," Working Paper 7899, National Bureau of Economic Research, 2000

[12] L. Wallach and P. Woodall, "Whose Trade Organization," New Press, New York, 2004.

[13] J. Stiglitz, "Globalization and Its Discontent," Allen Lane, London, 2002.

[14] S. Fischer, "Globalization and Its Challenge," Ely Lecture, American Economic Association Meeting, Washington D.C., January 2003.

[15] A. T. Kearney, "Measuring Globalization: Economic Reversals, Forward Momentum," Foreign Policy, Vol. Vol. 141, 2004, pp. 54-69.

[16] T. Andersen and T. Herbertsson, "Quantifying Globalization," Applied Economics, Vol. 37, No. 10, 2005, pp. 1089-1098. doi:10.1080/00036840500118200

[17] A. Heshmati, "Measurement of a Multidimensional Index of Globalization," Global Economy Journal, Vol. 6, No. 2, 2006, pp. 1-28. doi:10.2202/1524-5861.1117

[18] A. Dreher, "Does Globalization Affect Growth? Evidence from a New Index of Globalization," Applied Economics, Vol. 38, No. 10, 2006, pp. 1091-1110. doi:10.1080/00036840500392078

[19] S. N. Durlauf, P. A. Johnson and J. R. W. Temple, "Growth Econometrics," In: P. Aghion and S. N. Durlauf, Eds., Handbook of Economic Growth, Vol. 1, Elsevier, Amsterdam, 2005, pp. 555-680. doi:10.1016/S1574-0684(05)01008-7

[20] D. Rodrik, "Growth Strategies," In: P. Aghion and S. N. Daulauf, Eds., Handbook of Economic Growth, Vol. 1, Elsevier, Amsterdam, 2005, pp. 967-1014. doi:10.1016/S1574-0684(05)01014-2

[21] R. Hausmann, L. Pritchett and D. Rodrik, "Growth Acceleration," Journal of Economic Growth, Vol. 10, No. 4, December 2005, pp. 303-329. doi:10.1007/s10887-005-4712-0

[22] A. Harrison, "Openness and Growth: A Times-Series, Cross-Country Analysis for Developing Countries," Journal of Development Economics, Vol. 48, 1996, pp. 419447. doi:10.1016/0304-3878(95)00042-9

[23] D. Rodrik, A. Subramanian and F. Trebbi "Institutions Rule: The Primacy of Institutions over Geography and Integration in Economic Development," Journal of Economic Growth, Vol. 9, No. 2, 2004, pp. 131-165. doi:10.1023/B:JOEG.0000031425.72248.85

[24] B. Axel, M. Busse and S. Neuhaus, "Institutional Quality and the Gains from Trade," KYKLOS, Vol. 59, No. 3, 2006, pp. 45-368.

[25] K.-W. Li and X. Zhou, "Openness, Domestic Performance and Growth," Economic Letters, Vol. 107, No. 1, 2010, pp. 13-16. doi:10.1016/j.econlet.2009.12.012

[26] X. B. Zhou and K.-W. Li, "The Impact of Openness and Domestic Performance of Growth using Non-parametric Estimations," Applied Economics Letters, Vol. 18, No. 11, 2011, pp. 1065-1070. 
[27] D. Rodrik, "Has Globalization Gone too Far?" Institute for International Economics, Washington D.C., 1997.

[28] B. Sambit, S. Dowrick and J. Holley, "Institutions and Trade: Competitors or Complements in Economic Development?" Manuscript, The Australian National University, 2008.

[29] B. Lockwood, "How Robust Is the Foreign Policy-Kearney Globalisation Index?" The World Economy, Vol. 27, 2004, pp. 507-523. doi:10.1111/j.0378-5920.2004.00611.x

[30] A. Rencher, "Methods of Multivariate Analysis," 2nd Edition, Wiley-Interscience, New York, 2002. doi:10.1002/0471271357

[31] G. James and H. Kum, "Inequality and Economic Growth - Data Comparison and Econometrics Test," University of Texas Inequality Project, Working Paper Number 21, 2002.

[32] D. Dollar and A. Kraay "Institutions, Trade and Growth," Journal of Monetary Economics, Vol. 50, No. 1, 2003, pp. 133-162. doi:10.1016/S0304-3932(02)00206-4

[33] C. Fernandez, L. Eduardo and M. F. J. Steel, "Model Uncertainty in Cross-Country Growth Regressions," Journal of Applied Econometrics, Vol. 16, No. 5, 2001, pp. 563-576. doi:10.1002/jae.623

[34] X. Sala-i-Martin, "I Just Ran 2 Million Regressions," American Economic Review, Vol. 87, No. 2, 1997, pp. 178-183.

[35] United Nations, "United Nations Comtrade," 1998-2002, New York.

[36] B. Balassa, "Traded Liberalization and 'Revealed' Comparative Advantage," The Manchester School of Economic and Social Studies, Vol. 33, No. 2, 1965, pp. 99-123. doi:10.1111/j.1467-9957.1965.tb00050.x

[37] B. Balassa, “'Revealed' Comparative Advantage Revisited: An Analysis of Relative Export Shares of the Industrial Countries, 1953-1971," The Manchester School of Economic and Social Studies, Vol. 45, 1977, pp. 327-344. doi:10.1111/j.1467-9957.1977.tb00701.x

[38] B. Balassa, "The Changing Pattern of Comparative Advantage in Manufactured Goods," Review of Economics and Statistics, Vol. 61, No. 2, 1979, pp. 259-266. doi: $10.2307 / 1924594$

[39] B. Balassa, "Comparative Advantage in Manufactured Goods: A Reappraisal," Review of Economics and Statistics, Vol. 68, No. 2, 1986, pp. 315-319. $\mathrm{i}: 10.2307 / 1925512$

[40] International Monetary Fund, "International Financial Statistics," International Monetary Fund, Washington D.C., 1998-2002.

[41] United Nations, "Balance of Payments Statistics," New York, 1998-2002.

[42] International Telecommunication Union, "International Telecommunication Union Database," International Telecommunication Union, Geneva,1998-2002.

[43] International Telecommunication Union, "Netcraft Secure Server Surveys," International Telecommunication Union, Geneva, 1998-2002.

[44] World Tourism Organization, "Compendium of Tourism Statistics," New York, 1998-2002.

[45] Central Intelligent Agency, "The World Factbook," The Central Intelligent Agency, Washington D.C., 1998-2002.

[46] United Nations, "United Nations Development Program Indicators," New York, 1998-2002.

[47] World Bank, "World Development Indicators," The World Bank, Washington D.C., 1998-2002.

[48] Transparency House, "Corruption Index," Transparency House, Washington D.C., 1996-2003.

[49] World Bank, "Aggregate Governance Indicators," The World Bank, Washington D.C., 1998-2002.

[50] Heritage Foundation, "Index of Economic Freedom," The Heritage Foundation, Washington D.C., 1998-2002. 


\section{Appendix}

\section{Data}

All data are obtained from established international sources. The per capita GDP data are obtained from the World Development Indicators, The World Bank. The inter-industry trade index and the intra-industry trade index are compiled using the UN Comtrade Database, SITC Rev.3, for all the 62 economies with all commodities up to two-digit level.[35] The performance of inter-industry trade is estimated from an economy's revealed comparative advantage (RCA) index.[36-39] An economy's $R C A$ index can be calculated by:

$$
R C A_{i t, g}=\left(\left(X_{i g} / X_{w g}\right) /\left(X_{i} / X_{w}\right)\right)_{t},
$$

where $X_{i g}$ denotes economy $i$ 's export of commodity $g$, $X_{w g}$ is world export of commodity $g, X_{i}$ is economy $i$ 's total export and $X_{w}$ is total world exports, where $i=1, \cdots N, t=1, \cdots, T$ and $g=1, \cdots, G$. When the value of $R C A_{i t, g}$ exceeds unity, economy $i$ is said to have a revealed comparative advantage in good $g$ at time $t$. The total number of export industries of individual economies with revealed comparative advantage greater than unity is selected and normalized (NRCA) to form an indicator for the economy's inter-industry trade performance $\left(\right.$ TRCA $\left._{i t}\right)$ :

$$
T R C A_{i t}=\left(N R C A_{i} / M_{i} X X\{N R C A\}\right)_{t} .
$$

The intra-industry trade index (IIT) can be calculated as:

$$
I I T_{i t}=\left(\frac{\sum_{j=1}^{n_{j}}\left\{\left[1-\frac{\sum_{g}\left|X_{i j, g}-M_{i j, g}\right|}{\sum_{g}\left(X_{i j, g}+M_{i j, g}\right)}\right] * 100\right\}}{\operatorname{MAX}_{i}\left\{\sum_{j=1}^{n_{j}}\left(\left[1-\frac{\sum_{g}\left|X_{i j, g}-M_{i j, g}\right|}{\sum_{g}\left(X_{i j, g}+M_{i j, g}\right)}\right] * 100\right]\right\}},\right)_{t}
$$

where $X_{i j, g}$ is the export value of good $g$ from country $i$ to country $j, M_{i j, g}$ is the import value of $\operatorname{good} g$ to country $i$ from country $j$, and $n_{j}=$ total number of economy_i's trading partners. Equation (A3) shows the weighted average of individual industry indices, where the weights are the shares of industries in total trade.

The sources of data for the 17 factors in each of the Internal Factors Index and the External Factor Index shown in Appendix Table 1 are:

Table 1. The classification of external factors and internal factors.

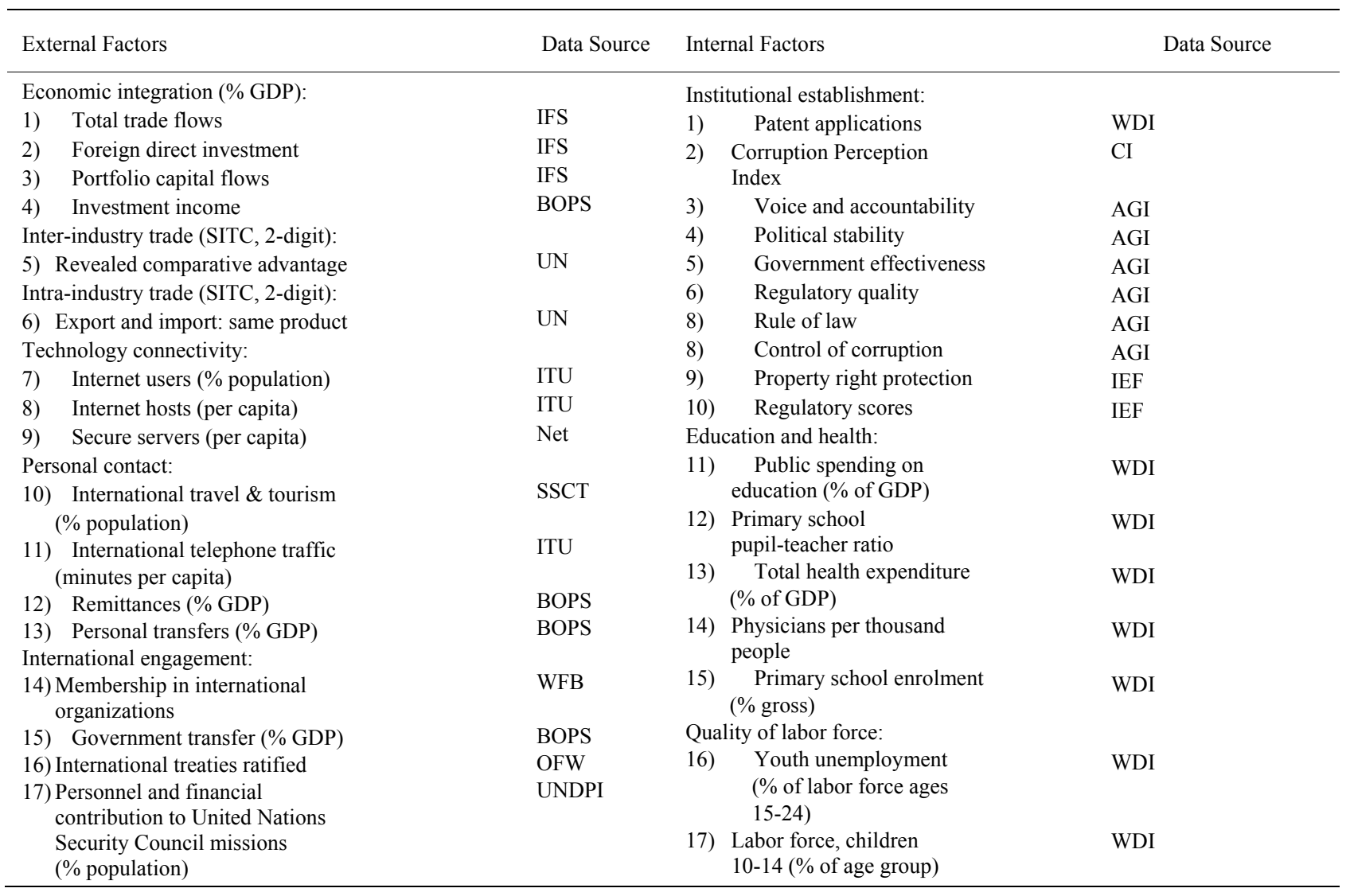


Table 2. External factors and internal factors indices: 1998-2002 average.

\begin{tabular}{|c|c|c|c|c|}
\hline \multirow{2}{*}{ Ranking } & \multicolumn{2}{|c|}{ External Factors Index } & \multicolumn{2}{|c|}{ Internal Factors Index } \\
\hline & Economies & Index & Economies & Index \\
\hline 1 & Ireland & 1.00 & Sweden & 0.93 \\
\hline 2 & United States & 0.70 & Switzerland & 0.91 \\
\hline 3 & Netherlands & 0.72 & Finland & 0.90 \\
\hline 4 & Switzerland & 0.65 & Denmark & 0.93 \\
\hline 5 & Sweden & 0.65 & United States & 0.89 \\
\hline 6 & Finland & 0.62 & Norway & 0.87 \\
\hline 7 & Singapore & 0.64 & Canada & 0.88 \\
\hline 8 & Denmark & 0.61 & Germany & 0.88 \\
\hline 9 & Austria & 0.60 & Singapore & 0.86 \\
\hline 10 & United Kingdom & 0.60 & Netherlands & 0.84 \\
\hline 11 & Canada & 0.60 & New Zealand & 0.83 \\
\hline 12 & New Zealand & 0.56 & Austria & 0.86 \\
\hline 13 & Australia & 0.50 & United Kingdom & 0.84 \\
\hline 14 & Norway & 0.48 & Australia & 0.85 \\
\hline 15 & Germany & 0.49 & Ireland & 0.80 \\
\hline 16 & France & 0.48 & Spain & 0.74 \\
\hline 17 & Hong Kong & 0.47 & France & 0.73 \\
\hline 18 & Portugal & 0.40 & Japan & 0.73 \\
\hline 19 & Spain & 0.38 & Portugal & 0.72 \\
\hline 20 & Italy & 0.37 & Hong Kong & 0.71 \\
\hline 21 & Czech Republic & 0.35 & Slovenia & 0.71 \\
\hline 22 & Israel & 0.32 & Italy & 0.70 \\
\hline 23 & Slovenia & 0.30 & Israel & 0.66 \\
\hline 24 & Hungary & 0.27 & Czech Republic & 0.63 \\
\hline 25 & Slovak Republic & 0.28 & Hungary & 0.63 \\
\hline 26 & Japan & 0.27 & Malaysia & 0.53 \\
\hline 27 & Malaysia & 0.26 & Chile & 0.60 \\
\hline 28 & Panama & 0.25 & Greece & 0.59 \\
\hline 29 & Greece & 0.24 & Poland & 0.56 \\
\hline 30 & Poland & 0.23 & Saudi Arabic & 0.52 \\
\hline 31 & Korea & 0.23 & Tunisia & 0.48 \\
\hline 32 & Croatia & 0.20 & Korea & 0.48 \\
\hline 33 & Argentina & 0.19 & Panama & 0.47 \\
\hline 34 & Chile & 0.17 & Slovak Republic & 0.47 \\
\hline 35 & Philippine & 0.16 & Argentina & 0.44 \\
\hline 36 & Brazil & 0.15 & Morocco & 0.41 \\
\hline 37 & Russian & 0.15 & Botswana & 0.43 \\
\hline 38 & Thailand & 0.15 & Brazil & 0.39 \\
\hline 39 & Mexico & 0.14 & Thailand & 0.40 \\
\hline 40 & China & 0.14 & Romania & 0.37 \\
\hline 41 & Turkey & 0.13 & Egypt & 0.36 \\
\hline 42 & Romania & 0.13 & South Africa & 0.38 \\
\hline 43 & South Africa & 0.14 & Croatia & 0.37 \\
\hline 44 & Indonesia & 0.12 & Sri Lanka & 0.34 \\
\hline 45 & Ukraine & 0.12 & Turkey & 0.32 \\
\hline 46 & Botswana & 0.10 & Peru & 0.32 \\
\hline 47 & India & 0.11 & Mexico & 0.30 \\
\hline 48 & Tunisia & 0.11 & Venezuela & 0.30 \\
\hline 49 & Colombia & 0.10 & Colombia & 0.30 \\
\hline 50 & Peru & 0.08 & Russian & 0.29 \\
\hline 51 & Senegal & 0.08 & Philippine & 0.28 \\
\hline 52 & Venezuela & 0.07 & India & 0.26 \\
\hline 53 & Nigeria & 0.07 & Iran & 0.21 \\
\hline 54 & Egypt & 0.07 & China & 0.22 \\
\hline 55 & Kenya & 0.06 & Indonesia & 0.16 \\
\hline 56 & Morocco & 0.05 & Ukraine & 0.21 \\
\hline 57 & Pakistan & 0.05 & Senegal & 0.19 \\
\hline 58 & Sri Lanka & 0.04 & Kenya & 0.13 \\
\hline 59 & Uganda & 0.04 & Pakistan & 0.12 \\
\hline 60 & Saudi Arabic & 0.03 & Uganda & 0.10 \\
\hline 61 & Iran & 0.03 & Bangladesh & 0.03 \\
\hline 62 & Bangladesh & 0.01 & Nigeria & 0.00 \\
\hline
\end{tabular}


IFS = International Financial Statistics, International Monetary Fund;[40]

BOPS = Balance of Payment Statistics, United Nations;[41]

$\mathrm{UN}=$ United Nations Comtrade, United Nations;[35]

ITU = International Telecommunication Union Database, International Telecommunication Union;[42]

Net $=$ Netcraft Secure, International Telecommunication Union; [43]

SSCT $=$ Server Surveys Compendium of Tourism Statistics, World Tourism Organization; [44]

WFB = The World Factbook, Central Intelligence Agency;[45]

OFW = Official websites of selected basket of treaties;

UNDPI = United National Development Program Indicators, United Nations; [46]

WDI = World Development Indicators, World Bank;[47]

CI = Corruption Index 1996-2002, Transparency House; [48]

AGI = Aggregating Governance Indicators 1996-2004,
World Bank;[49]

IEF $=$ Index of Economic Freedom, Heritage Foundation.[50]

There are few exceptions. For example, Hong Kong has probably little international engagement in government transfer and does not engage in financial contribution to the United Nations Security Council missions. The few missing values in the country series are replaced by the average of the immediate past and future years. In the EFI, the maximum number of missing economies in the 1998-2002 sample periods is 4, and their percentage ranged between $5.9 \%$ and $11.8 \%$. For the IFI, the corresponding figures for the maximum number of missing economies are 40, and the percentage ranged between $5.9 \%$ and $35.3 \%$. A complete set of data is obtained for the three years of 1998-2001, while some data in 2002 are either provisional or unavailable. In the case of IFI, the few provisional data of 2002 are replaced by the corresponding figures in 2001. 